\title{
An Approach to Risk Assessment of an Investment Project for the Development of a Coal Deposit
}

\author{
Marina V. Pisarenko $1 *$ [ORCID 0000-0003-0096-1437], \\ Andrey B. Efremenkov 2[ORCID 0000-0003-3078-5972]
}

\author{
${ }^{1}$ The Federal Research Center of Coal and Coal Chemistry of Siberian Branch of the Russian Academy of \\ Sciences, Kemerovo, Russia \\ ${ }^{2}$ Yaroslav-the-Wise Novgorod State University, Veliky Novgorod, Russia \\ mvp@icc.kemsc.ru
}

\begin{abstract}
To assess the risk of an investment project for the development of coal deposits in conditions of the initial data uncertainty, methods of fuzzy logic are used, which allow operating quantitative and qualitative information, including the one difficult to formalize. To take into account the uncertainty of the initial geological information, on the basis of which all decisions on the development of a coal deposit are made, it is suggested to use an objective multi-variance of ideas (uncertainty of knowledge) about the geology of the deposit, based on the results of geological exploration. Such multi-variant mining and geometrical models of field indicators as pessimistic, design (traditional) and optimistic models taking into account the uncertainty of geological information are built. The values of the control parameters (minimum, design and maximum) are determined according to multi-variant models of the main indicators of the deposit (seam thickness, seam ash content, etc.). The price of marketable products, production volume, capital and operating costs are taken as regulating parameters. The degree of the current criterion value belonging - net discounted income - to a fuzzy set is established by a triangular function, which is determined by the minimum, design and maximum value of the criterion. The average value of the degree of belonging of the current criterion value to a fuzzy set for all regulatory parameters is taken as a quantitative assessment of the project efficiency (sustainability); the closer this value is to 1 , the more sustainable is the project. Assessment of the project's efficiency by a set of economic criteria involves the formation of a linguistic term-set of project's states: "inefficient project", "project of average efficiency", "efficient project", "highly efficient project", etc., with expert assignment of values from 0 to 1 to terms. The degree of a fuzzy set membership of the current value for each of the accepted criteria is also determined by a triangular function. The average value of the membership degree according to the set of accepted criteria (for example, net present value and internal rate of return) is correlated with the linguistic set, thereby establishing the project sustainability according to the set of criteria. The proposed approach makes possible the quantitative assessment of the risks of investment projects for the coal deposits development caused by the uncertainty (fuzziness) of knowledge about the geology of a coal deposit at the pre-design stage.
\end{abstract}

Keywords: coal deposits, mining project risks, fuzzy logic, information uncertainty, investment project efficiency, deposit multi-variant geometrization

\section{INTRODUCTION}

Industrial and economic activity is characterized by uncertainty of conditions and factors. If managerial decisions are made in conditions of incomplete information about the object of management, the set goals are either achieved incompletely or not achieved at all. A risk is the measure of the possibility of undesirable result that may or may not occur.

The mining industry, besides the risks inherent in all production facilities, has specific risks geological, technological, mining [1-3], which occur at all stages from development to project implementation. These risks emerge, because from the start of designing a deposit development project and up to planning and performing mining activities, 
decisions are made on the basis of geological ideas about the forms and properties of the placement of minerals in the subsoil. These ideas are formed in the process of geological study of the subsoil and objectively have one or another level of uncertainty (fuzziness) of knowledge.

The development of mining projects based on incomplete and inaccurate initial geological information leads to unforeseen situations during their implementation and, as a consequence, to losses and damages, and in some cases - to abandoning the deposit development [2, 3]. The above types of risks (geological, mining and technological), as shown by a survey of leading analysts, are the most significant for mining projects $[2,3]$. Therefore, the assessment of the degree of geological knowledge [uncertainty (error) of geological information] and risk analysis is a mandatory and crucial stage in the development of mining projects controlled by regulatory documents. However, in practice, it is carried out formally, according to the traditional scheme for assessing financial risks and without taking into account the uncertainty of geological knowledge about the development object [3].

\section{MATERIALS AND METHODS}

Risk assessment involves a qualitative analysis and quantitative assessment of the occurrence of undesirable events. However, in the design materials, a qualitative analysis (identification of possible risks and the reasons for their occurrence) is limited only to an overview of the current trends in the world coal markets, without any conclusions.

Quantitative risk assessment involves the calculation of numerical indicators using quantitative methods - statistical, scenarios, simulation, sensitivity analysis, etc. The lack of relevant information limits the use of calculation methods, therefore, in the design materials it is represented only by sensitivity analysis determining the volatility of the main indicators of project performance (discounted income and internal rate of return) with the "swinging" regulatory parameters (volume of production, price of a commodity product, investment costs, production costs and sales). The "swing" of the regulatory parameters is taken at the level of $\pm 15( \pm 20) \%$ without justification; net present value (NPV), internal rate of return (IRR) are determined, and the result is presented in the form of graphs. The coefficient of elasticity is used to estimate the sensitivity of NPV and IRR from one of the regulatory parameters, taking the rest to be constant. This assumption is very arbitrary; it does not fully correspond to reality and does not provide an adequate assessment of the geological risk most significant for a mining project.

Practice shows that risk assessment under conditions of various kinds of uncertainty presupposes interval presentation of initial quantitative and linguistic indicators, as well as knowledge that is difficult to formalize. The quality of such an assessment directly depends on the approach used, which should provide an acceptable formalization of information uncertainty and an adequate solution to the problem. Application of traditional probabilistic and deterministic methods for these purposes does not give an adequate assessment [3-7]. More promising are the new approaches [3-7] based on the theory of fuzzy sets, which are "free from probabilistic axiomatics and from problems with justifying the choice of probabilistic weights, and on the other hand, include all possible scenarios for the development of events" [7]; therefore, they turn out to be the most effective for assessing business risks in conditions of various kinds of the initial information uncertainty. The use of fuzzy sets makes it possible to structure the uncertainty of the initial data and obtain a formal boundary separating knowledge from ignorance, based on the functions of a fuzzy number belonging to some clear set [7].

In [6], it is argued that the use of fuzzy sets in relation to the assessment of oil and gas investment projects has a number of advantages over traditional methods. In particular, this approach allows formulating and analyzing a more complete range of possible scenarios, comprehensively assessing the degree of influence of risk factors on the efficiency of a project by one criterion and by a set of economic criteria.

The research aim is to develop an approach to quantifying the risk of an investment project, taking into account the uncertainty of geological information about the field. Research objectives are to substantiate the list of initial data, evaluation criteria and the method of their interval presentation; to adapt the approach proposed in [6] to projects for the development of a coal deposit.

\section{RESULTS}

According to the approach based on the theory of fuzzy sets [4-7], the assessment of a project in regards to one of the main efficiency criteria - NPV 
- involves the formalization of the initial data and the target criterion. The following parameters are taken as the initial regulatory ones: product price, production volume, capital and operating costs, which, due to the uncertainty of their values at the time of project development, are set at intervals. The NPV values corresponding to the initial parameters form a fuzzy set and are calculated in the part "Assessing the risk and sensitivity of the project" of the design draft.

The membership function, which makes it possible to assess the degree of membership of the criterion value to a fuzzy set, is assumed to be triangular and is put down as $\mathrm{NPV}=\left(\mathrm{NPV}_{\min }\right.$; $\left.\mathrm{NPV}_{0} ; \mathrm{NPV}_{\text {max }}\right)$. The arguments $\mathrm{NPV}_{\text {min }}, \mathrm{NPV}_{0}$, $\mathrm{NPV}_{\text {max }}$ (the minimum, design and maximum value of the fuzzy number NPV, respectively) are called significant points and are compared with possible scenarios of the initial data - pessimistic, design and optimistic.

The rules for the membership of the current value $G_{i}$ to the fuzzy set $\mathrm{NPV}=\left(\mathrm{NPV}_{\min } ; \mathrm{NPV}_{0}\right.$; $\mathrm{NPV}_{\max }$ ) is described by a function that has the form of the following mathematical relationship (1) [8]:

$$
a_{1}=\left(\begin{array}{c}
0, G \leq N P V_{\text {min }} \\
\frac{G-N P V_{\min }}{N P V_{0}-N P V_{\min }}, N P V_{\min }<G<N P V_{0} \\
1, G=N P V_{0} \\
\frac{N P V_{\max }-G}{N P V_{\max }-N P V_{0}}, \quad N P V_{0}<G<N P V_{\max } \\
0, G \geq N P V_{\max }
\end{array}\right)
$$

The calculation result for a real mining project is presented in Table 1.

Table 1. Multivariant NPV calculation

\begin{tabular}{|c|c|c|c|}
\hline No & Indicator Fluctuations (+/-), \% & NPV, min of rubles & The Membership Function $a_{1}, a$ unit share \\
\hline \multicolumn{4}{|c|}{ Selling price of marketable products } \\
\hline 1 & -30 & -1450 & 0.00 \\
\hline 2 & -20 & 700 & 0.33 \\
\hline 3 & -15 & 1775 & 0.50 \\
\hline 4 & -10 & 2850 & 0.67 \\
\hline 5 & 0 & 5000 & 1.00 \\
\hline 6 & 10 & 7150 & 0.50 \\
\hline 7 & 15 & 8225 & 0.25 \\
\hline 8 & 20 & 9300 & 0.00 \\
\hline \multicolumn{4}{|c|}{ Sales volume of commercial products } \\
\hline 1 & -30 & -550 & 0.14 \\
\hline 2 & -20 & 1300 & 0.43 \\
\hline 3 & -15 & 2225 & 0.57 \\
\hline 4 & -10 & 3150 & 0.71 \\
\hline 5 & 0 & 5000 & 1.00 \\
\hline 6 & 10 & 6850 & 0.57 \\
\hline 7 & 15 & 7775 & 0.35 \\
\hline 8 & 20 & 8700 & 0.14 \\
\hline \multicolumn{4}{|c|}{ Operating costs } \\
\hline 1 & +20 & 3200 & 0.72 \\
\hline 2 & +15 & 3650 & 0.79 \\
\hline 3 & +10 & 4100 & 0.86 \\
\hline 4 & 0 & 5000 & 1.00 \\
\hline 5 & -10 & 5900 & 0.79 \\
\hline 6 & -15 & 6350 & 0.69 \\
\hline 7 & -20 & 6800 & 0.58 \\
\hline \multicolumn{4}{|c|}{ Capital investments } \\
\hline 1 & +20 & 3400 & 0.75 \\
\hline 2 & +15 & 3800 & 0.81 \\
\hline 3 & +10 & 4200 & 0.88 \\
\hline 4 & 0 & 5000 & 1.00 \\
\hline 5 & -10 & 5800 & 0.81 \\
\hline 6 & -15 & 6200 & 0.72 \\
\hline 7 & -20 & 6600 & 0.63 \\
\hline \multicolumn{3}{|c|}{$N P V_{\min }=-1450 ; N P V_{0}=5000 ; N P V_{\max }=9300$} & $A_{\text {aver }}=0.61$ \\
\hline
\end{tabular}

Source: Compiled by the authors

As a quantitative assessment of the efficiency (sustainability) of an investment project, the average value of $a_{\text {aver }}$ is taken over all estimates $a_{l}$. The sustainability index $\lambda$ is in the interval $[0 ; 1]$. The closer $a_{\text {aver }}$ is to 1 , the more sustainable is the project. For the analyzed object, $a_{\text {aver }}=0.61$ (Table $1)$, which characterizes the project as quite sustainable. 
To calculate the risk of an emergence $(R E)$, for which we take the option with $\mathrm{NPV} \leq 0$, we use the formula (2) proposed in [7]:

$$
\begin{gathered}
R E=\frac{-\mathrm{NPV}_{\text {min }}}{\mathrm{NPV}_{\max }-\mathrm{NPV}_{\min }}+ \\
\frac{\mathrm{NPV}_{0}}{\mathrm{NPV} V_{\max }-\mathrm{NPV}_{\min }} \ln \frac{\mathrm{NPV}_{0}}{\mathrm{NPV}-\mathrm{NPV} V_{\min }} .
\end{gathered}
$$

In [7], it was shown that with a risk of up to $10 \%$, the risk function increases slowly; in the range from $10 \%$ to $20 \%$, a borderline situation is observed; and over $20 \%$, the function increases sharply, and the risk is assessed as unacceptable. For the analyzed investment project, the risk of an emergency is $3.8 \%$ and it is acceptable.

The above considered approach provides a quantitative assessment of the efficiency of an investment project according to one criterion - NPV, as well as the risk of an emergency. The assessment of the project efficiency based on a set of such economic criteria as NPV and IRR, involves a slightly different approach [6].

The project efficiency cannot be accurately measured, therefore, to describe it, a linguistic termset of states of the project $E$ is formed with expert assignment of values to the terms:

$E \in[0 ; 0.2]-$ project is inefficient;

$E \in[0.21 ; 0.44]$ - project is of low efficiency;
$E \in[0.45 ; 0.55]$ - project is of average efficiency;

$E \in[0.56 ; 0.69]$ - project is of high efficiency;

$E \in[0.7 ; 1]-$ project is of utmost efficiency.

It should be noted that the adopted integral values of $E$ are original; they take into account the specifics of a particular mining project and do not pretend to be absolute. As noted above, the initial data that have a significant impact on the economic performance of the project are price, production volume, capital and operating costs. Pure NPV $\left(x_{i 1}\right)$ and IRR $\left(x_{i 2}\right)$ are taken as evaluation criteria. For each criterion $x_{i j}$, a fuzzy set is formed, the values of which are correlated with the triangular membership function $e\left(x_{i j}\right)$ according to the formula (3) [8]:

$$
e\left(x_{i j}\right)=\left(\begin{array}{c}
0, x_{i j}=x_{\text {minj }}, \quad \text { OR } x_{i j}<0 \\
\frac{x_{i j}-x_{\text {minj }}}{x_{\text {maxj }}-x_{\text {minj }}}, x_{\text {minj }}<x_{i j}<x_{\text {maxj }} \\
1, x_{i j}=x_{\text {maxj }}
\end{array}\right) .
$$

The calculation result for a real mining investment project is summarized in Table 2.

The complex indicator of the investment project efficiency $E$ is equal to the average value of all $e\left(x_{i j}\right)$. In the considered case, $E=0.51$, and, according to the linguistic term-set, the mining project has an average efficiency. The risk of an emergency $(\mathrm{NVP} \leq 0)$ determined by formula (2) is $4.1 \%$, i.e. acceptable.

\begin{tabular}{|c|c|c|c|c|c|}
\hline \multirow{2}{*}{\multicolumn{2}{|c|}{$\frac{\text { Indicator Fluctuation }(+,-), \%}{j}$}} & \multicolumn{2}{|c|}{ NPV, thousand of rubles } & \multicolumn{2}{|c|}{ IRR, \% } \\
\hline & & $x_{i 1}$ & $e\left(x_{i 1}\right)$ & $x_{i 2}$ & $\epsilon\left(x_{i 2}\right)$ \\
\hline \multicolumn{6}{|c|}{ Product price } \\
\hline 1 & -20 & -700 & 0.00 & 6.3 & 0.00 \\
\hline 2 & -15 & -248 & 0.00 & 8.7 & 0.11 \\
\hline 3 & -10 & 200 & 0.25 & 11.1 & 0.22 \\
\hline 4 & 0 & 1080 & 0.50 & 17.7 & 0.52 \\
\hline 5 & +10 & 2020 & 0.76 & 24.2 & 0.82 \\
\hline 6 & +15 & 2480 & 0.89 & 26.1 & 0.91 \\
\hline \multirow[t]{2}{*}{7} & +20 & 2880 & 1.00 & 28.0 & 1.00 \\
\hline & & & 0.48 & & 0.51 \\
\hline \multicolumn{6}{|c|}{ Volume of sales } \\
\hline 1 & -20 & 0 & 0.19 & 10.1 & 0.17 \\
\hline 2 & -15 & 200 & 0.25 & 12.1 & 0.26 \\
\hline 3 & -10 & 500 & 0.33 & 14.1 & 0.36 \\
\hline 3 & 0 & 1080 & 0.50 & 17.7 & 0.52 \\
\hline 4 & +10 & 1710 & 0.67 & 21.2 & 0.68 \\
\hline 5 & +15 & 2000 & 0.75 & 24.1 & 0.82 \\
\hline \multirow[t]{2}{*}{6} & +20 & 2400 & 0.87 & 27.2 & 0.95 \\
\hline & & & 0.51 & & 0.54 \\
\hline \multicolumn{6}{|c|}{ Net cost } \\
\hline 1 & -20 & 2400 & 0.86 & 26.0 & 0.91 \\
\hline 2 & -15 & 2000 & 0.75 & 24.5 & 0.84 \\
\hline 3 & -10 & 1710 & 0.67 & 22.2 & 0.72 \\
\hline 4 & 0 & 1080 & 0.50 & 17.7 & 0.52 \\
\hline 5 & +10 & 500 & 0.33 & 14.0 & 0.35 \\
\hline 6 & +15 & 100 & 0.22 & 11.4 & 0.23 \\
\hline
\end{tabular}

Table 2. Influence of regulatory parameters on the values of economic criteria and membership functions 


\begin{tabular}{|c|c|c|c|c|c|}
\hline 7 & +20 & -300 & 0.00 & 8.8 & 0.11 \\
\hline & & & 0.47 & & 0.53 \\
\hline \multicolumn{6}{|c|}{ Investments } \\
\hline 1 & -20 & 1598 & 0.64 & 25.2 & 0.86 \\
\hline 2 & -15 & 1498 & 0.61 & 23.1 & 0.77 \\
\hline 3 & -10 & 1380 & 0.58 & 20.0 & 0.63 \\
\hline 4 & 0 & 1080 & 0.50 & 17.7 & 0.52 \\
\hline 5 & +10 & 850 & 0.30 & 15.8 & 0.44 \\
\hline 6 & +15 & 640 & 0.37 & 14.0 & 0.35 \\
\hline \multirow[t]{3}{*}{7} & +20 & 430 & 0.31 & 12.1 & 0.26 \\
\hline & & & 0.49 & & 0.55 \\
\hline & $\begin{array}{c}x_{\min } \\
x_{\max } \\
x_{0}\end{array}$ & $\begin{array}{l}-700 \\
2880 \\
1080\end{array}$ & 0.49 & $\begin{array}{c}6.3 \\
28.0 \\
17.7\end{array}$ & 0.53 \\
\hline
\end{tabular}

Source: Compiled by the authors

Taking into account the specifics of the development of coal deposits, it is suggested to use the proposed in [6] and described above approach in the part "Assessment of risk and sensitivity of the project" of the design solutions for the coal deposits development.

\section{DISCUSSION}

The risk calculated by formula (2) is in direct proportion to the maximum and minimum values of the indicator, the values of which determine the minimum and maximum values (interval) of the regulatory parameters - the uncertainty of the initial data. Both an excessive increase and a decrease in the limit of the interval of regulatory parameters are undesirable: in the first case, the risks will be underestimated, and the project efficiency will be overestimated, and in the other case, on the contrary, the efficiency will be underestimated and the project will be blocked.

Therefore, the adequacy of the assessment depends on the objectivity of establishing the width of the interval of regulatory parameters: the production volume, the price of commercial products, the net price, investments, etc., the values of which are determined by the mining-geological and mining-technical conditions for the deposit development, and their possible values depend on the uncertainty of geological knowledge about the subsoil.

The mining-geological and mining-technical conditions of the deposit determine the volume of production, the quality of the marketable product, the technology of developing reserves and other indicators, therefore the limit of the possible values of these parameters is connected with the uncertainty (error) of geological information, i.e. with the degree of geological exploration of the field, which can be estimated by the method of multivariant geometrization of the field.
The idea of multivariant geometrization is that geological ideas about the forms and properties of the distribution of minerals in the depths are always uncertain. Therefore, the mining-geometric models (so-called traditional models) formed according to the results of geological exploration and adopted for design have inherent uncertainty, which implies the presence of alternative (pessimistic and optimistic) mining geometric models $[8,9]$.

Alternative models, including all possible implementations, display the boundary - the minimum and maximum values of the deposit indicators, which are proposed to be used for determination of the regulatory parameters range (production volumes, prices, etc.) according to the approach based on the theory of fuzzy sets $[6,7]$.

Thus, the assessment of the geological risk of an investment project for the development of coal deposits presupposes:

- generation of multi-variant mining-geometric models of deposit indicators (pessimistic, traditional and optimistic models), according to the approach proposed in $[9,10]$ and taking into account the uncertainty of the concept of the subsoil;

- determination of possible values of the main deposit indicators in regards to the technological design solutions for the deposit development by combining multi-variant mining-geometric models of indicators and geo-technological solutions for the deposit development;

- setting the limits of the regulatory parameters intervals; "swinging" the criteria for project performance (NPV, IRR);

- quantitative assessment of the sensitivity and risk of a mining project using the formulas (1)-(3). 


\section{CONCLUSION}

In conclusion, it should be noted that the use of the theory of fuzzy sets in assessing the risks of mining investment projects makes it possible to use various kinds of information (quantitative and qualitative), including the one interval-fuzzy specified; to expand the scope of possible scenarios for the implementation of the solutions. Setting of the interval values of the main initial parameters based on multi-variant modeling of field indicators allows taking into account the uncertainty of geological information when making geotechnological decisions on the development of subsoil.

\section{AUTHORS' CONTRIBUTIONS}

The authors made an equal contribution to the study: collection and analysis of material; definition of goals and objectives, research methods; formulation and scientific substantiation of conclusions, registration of key research results in the form of an article.

\section{REFERENCES}

[1] G.Yu. Boyarko, "Strategic mineral risks of mining industry", National Geology, 2003, vol. 4(5), pp. 28-32. (In Russ.).

[2] T. Rogova, S. Shaklein, "Evaluation of Geological Risks of Commercial Development of Complex Structured Coal Deposits", in Proceedings of the $\mathrm{IV}^{\text {th }}$ International Innovative Mining Symposium, E3S Web of Conferences, 2019, vol. 105, p. 01017. DOI: $10.1051 / \mathrm{e} 3$ sconf/201910501017

[3] "Methodical recommendations for the feasibility study of conditions for calculating reserves of solid mineral deposits. Coals and Oil Shale" [Metodicheskiye rekomendatsii po tekhniko-ekonomicheskomu obosnovaniyu konditsiy dlya podscheta zapasov mestorozhdeniy tverdykh poleznykh iskopayemykh. Ugli i goryuchiye slantsy], Moscow, 2007. 49 p. (In Russ.).

[4] P.M. Derevyanko, "Application of the theory of fuzzy sets in the financial and investment analysis of an enterprise's activities under conditions of uncertainty" [Primeneniye teorii nechetkikh mnozhestv $\mathrm{v}$ finansovom $\mathrm{i}$ investitsionnom analize deyatel'nosti predpriyatiya $\mathrm{v}$ usloviyakh neopredelennosti], in Proceedings of the VIII SPC of students and graduate students of SPbGIEU, Management and economics in the work of young researchers INZHEKON-2005 [Menedzhment i ekonomika $\mathrm{v}$ tvorchestve molodykh issledovateley INZHEKON], St. Petersburg: SPbGIEU Publ., 2005, pp. 98-99. (In Russ.).

[5] A.O. Nedosekin, "Application of the theory of fuzzy sets to financial management problems" [Primeneniye teorii nechetkikh mnozhestv $\mathrm{k}$ zadacham upravleniya finansami], Audit and Financial Analysis, 2000, vol. 2. (In Russ.). Retrieved from http://www.cfin.ru/press/afa/2000-2/08.shtml

[6] A.N. Dmitrievsky, N.A. Yeremin, Yu.G. Bogatkina, O.N. Sardanashvili, "Assessment of technical and economic efficiency of investment projects of development of oil and gas deposits based on application of fuzzy logic", Izvestiya Tula State University. Earth Science, 2019, vol. 4, pp. 340352. (In Russ.).

[7] A.O. Nedosekin, "Methodological foundations for modeling financial activities using fuzzy multiple descriptions" [Metodicheskiye osnovy modelirovaniya fina nsovoy deyatel'nosti s ispol'zovaniyem nechetko-mnozhestvennykh opisaniy], Doctoral dissertation, St. Petersburg, 2003. (In Russ.).

[8] M.V. Pisarenko, S.V. Shaklein, "Recommendations on integrated evaluation of preparedness of coal deposits for mining", IOP Conference Series: Earth and Environmental Science on Challenges for Development in Mining Science and Mining Industry, 2019, vol. 262, p. 012067. DOI: 10.1088/1755$1315 / 262 / 1 / 012067$

[9] M. Pisarenko, “Assessement of technological preparedness coal deposits to a rational industrial development", in Proceedings of the VII ISC "Problems of Complex Development of Georesources", E3S Web of Conferences, 2018, vol. 56, p. 04023 . DOI: $10.1051 / \mathrm{e} 3$ sconf/20185604023

[10] A.I. Kopytov, T.B. Rogova, S.V. Shaklein, "Evaluation of expected errors in geometrization of coal deposits at the stage of exploration and operation", Gornyi Zhurnal, 2020, vol. 4, pp. 4-9. (In Russ.). DOI: 10.17580/gzh.2020.04.01 